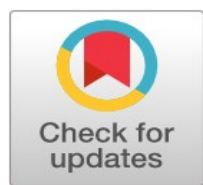

\title{
Cross-cultural interaction and job satisfaction in cross-cultural organizations: A case study of two Thai companies founded and managed by Chinese people
}

\author{
Xiaoyan $\mathrm{Li}^{*}$ \\ University of the Thai Chamber of Commerce, Bangkok, Thailand
}

\author{
Keywords \\ Job satisfaction \\ Cross-culture management \\ Work psychology \\ Received: 5 September 2017 \\ Accepted: 23 October 2017 \\ Published: 4 December 2017
}

\begin{abstract}
Cross-cultural work environments pose a particular challenge for the organizations that set up and operate a company abroad, especially in terms of job satisfaction, employee retention and motivation. This article aims to investigate cross-cultural interactions between Thai and Chinese people, who work in Thailand in Thai-registered companies, and how cultural differences in working practices affect job satisfaction. It found that in the context of such cross-cultural organizations, cultural differences may not directly affect job satisfaction and commitment, but may aggravate existing organizational problems if cultural differences are not resolved. It proposes a cross-cultural awareness strategy that allows organization to adequately deal with the challenges of cross-cultural interactions in the workplace.
\end{abstract}

\section{INTRODUCTION}

With an increase in globalization over the last decades, many enterprises have turned their attention to overseas markets and set up companies outside their own countries. Chinese enterprises investing in Thailand, for instance, have increased significantly between 2007 and 2012 (Li, Ruangkanjanases \& Chen, 2014), resulting in 240 Chinese new projects in Thailand between 2008 and 2014 (Broad of Investment, 2017). Managing or participating in the running of a company in another country requires not only economic, political, and legal considerations, but also needs a focus on organizational aspects such as cross-cultural interaction and cultural differences in working practices.

While there is a vast amount of cross-cultural organizational behaviour research, it tends to primarily focus on stark differences across continents, such as North American and East Asian or Western European countries. Cross- cultural studies within Asia are spare and generally tend to be comparative based on broad cultural groupings, rather than showing differences in routine practices. While crosscultural organizational behaviour research investigates a broad range of topics, the moderating role of different cultures in terms of job satisfaction is generally underexplored (Ardyanfitri \& Wahyuningtyas, 2016; Bonache, 2005; Hui \& Yee, 1999) and specially lacks empirical research across different Asian cultures.

This article aims to investigate the relationship between cross-cultural workplace interactions and job satisfaction in the context of Thai and Chinese cultures. It is based on an in-depth empirical analysis of two companies registered and operating in Thailand that were founded and are managed by Chinese nationals, with more than two-thirds of employees being Thai nationals. It aims to show how cultural differences manifest themselves in day-to-day organi-

\footnotetext{
* Corresponding author: Xiaoyan Li

†Email: sylvia410@163.com
} 
zational practices at work and how these differences affect job satisfaction to some extent. It furthermore shows how individuals adapt to cultural differences and points to the role management can play in facilitating adequate crosscultural interaction.

The article commences with an overview of the literature on cross-cultural organizational behaviour research, the psychology of acculturation, and a social history of interlink between Chinese and Thai people. This is followed by methodology, analysis, and discussion sections.

\section{LITERAT URE REVIEW}

International management is a prominent research topic that increased significantly at the beginning of the $21^{\text {st }}$ century (Kirkman \& Law, 2005). There is a vast amount of cross-cultural organizational behaviour research (Gelfand, Erez \& Aycan, 2007; Tsui, Nifadkar \& Ou, 2007; Yusof, Munap, Badrillah, Ab Hamid \& Khir, 2017) often based on Hofstede's cultural value framework (Kirkman, Lowe \& Gibson, 2006). In particular, there is a strong focus on differences across national contexts in terms of individualism/collectivism and power distance, often in terms of stark differences across continents, such as North American and East Asian or Western European countries.

While cross-cultural organizational behaviour research investigates a broad range of topics, there are some studies on the moderating role of different cultures in terms of job satisfaction or organizational commitment (Bo Shing \& Xiaodie, 2017; Tsui et al., 2007). For example, Huang \& Van de Vliert (2003) examines the role of culture in the relationship between job characteristics and job satisfaction, using a sample comprising of 49 countries. Their findings show that the link between intrinsic job characteristics (such as emotional achievement, self-realization, and identification of tasks) see (Weiss, Dawis \& England, 1967) and job satisfaction is stronger in richer countries, countries with better governmental social welfare programs, more individualistic countries, and smaller power distance countries. Hui, Au \& Fock (2004) examining the moderating effect of power distance on the relationship between empowerment and job satisfaction across 33 countries generally, and specifically between Canadian and Chinese hotel employees, show that the relationship between empowerment and job satisfaction was stronger in countries with lower power distances. Similarly, Robert, Probst, Martocchio, Drasgow \& Lawler (2000) examining the moderating role of culture in the relationship between employee empowerment and job satisfaction, found that empowerment was negatively associated with satisfaction in India but positively associated in the United States, Mexico, and Poland. Based on the concepts of individualism/collectivism and power distance, these authors suggest that such practices would be more common in some cultures than in others thereby affecting job satisfaction.

Although the literature on cross-cultural organizational behaviour research has had substantial input from the discipline of psychology, studies of job satisfaction in terms of acculturation or adaptation are mainly in the interdisciplinary field of intercultural relations or (health care sector) employment studies with immigration context. The deployment of conceptual frameworks of acculturation and adaptation, such as Berry (1997) including its cultural adaptation strategies: i.e., assimilation, separation, integration, and marginalization, is rare as the focus is usually on wider cultural comparisons rather than day-to-day interaction or cultural transition.

Ea, Griffin, L'eplattenier \& Fitzpatrick (2008) investigated the relationship between acculturation and job satisfaction of Filipino registered nurses, educated in the Philippines, who are working in the United States; they found that higher levels of acculturation to US culture significantly predicted perception of higher job satisfaction among this group of Filipino nurses. Similarly, a review of studies on expatriate job satisfaction recommends for HR strategies that enhance the acculturation and adjustment of an expatriate to increase their job satisfaction (Ardyanfitri \& Wahyuningtyas 2016; McCaughey \& Bruning, 2005). Likewise, Au, Garey, Bermas \& Chan (1998) found that Chinese immigrant restaurant workers in New York City who were more acculturated had also higher levels of job satisfaction. Based on Berry's work on acculturation process, Lu, Samaratunge \& Härtel (2012) investigated Chinese immigrants in Australia in terms of their attitudes toward acculturation strategies, and the relationship between different acculturation strategies and job satisfaction. They found that those immigrants who adopted an assimilation strategy report significantly higher levels of job satisfaction than those who adopted a separation strategy.

Finally, a diverse range of social sciences literature on East and Southeast Asia points to an interlinked social history of Chinese and Thai people. Burusratanaphand (1995) argues that the relationship between Chinese in Thailand and Thai people is complex. Historically the Chinese immigrants in Thailand were commercially important, but were regarded as outsiders. The close relationships between Thai elites and Chinese businesses in Thailand were 
primarily pragmatic and not based on long-term cultural assimilation. Ahlstrom, Young, Ng \& Chan (2004) and Yeung (2006) argue that overseas entrepreneurial Chinese in Southeast Asia have retained distinct characteristics of running businesses, such as family patriarchal control, centralized decision-making, and the implementation of guanxi. In contrast Thai people, as Lewis \& Gates (2005) argues, tend to be more pragmatic and flexible in terms of authority, especially discussion across hierarchical levels is not unusual in Thai businesses. This can be traced back to Buddhist influences on Thai culture, where competition traditionally was discouraged and change was often met with reluctance.

Nonetheless as Franco (2015) highlights the stark distinctions between village-based Thai culture and the culture of overseas Chinese cannot easily be applied to urban Thais. Hofstede's (2003) grouping of Thailand displaying weak uncertainty avoidance and a lower power distance, while China showing strong uncertainty avoidance and a hierarchical pyramid as the implicit model of organization, may be limited in hybrid contexts such as business settings that are dominated by Thai people of Chinese decent. As Franco (2015) suggests, Thai people who have migrated from rural to urban areas in Thailand have to undergo forms of acculturation to participate in businesses beyond street markets.

\section{METHODOLOGY}

Empirical research conducted for this study is based on two cases of Thai companies that were founded and managed by Chinese people. It is an in-depth analysis in the forms of detailed descriptions (Law, 2004) that aims to show the specific context of cross-cultural interaction and job satisfaction from an inside perspective in explanatory ways. As such this research is not aiming to give a "General Theory", but hopes to provide a detailed study of specific cases, through understanding a wider range of concepts that have emerged in the current academic discussions of management and organizational studies (Epifanova \& Hild, 2015).

This study deployed both informal conversational interviews (Spradley, 1979) and standardized, non-scheduled, open-ended question-based interviews (Briggs, 1986). The field research was conducted in two phases; phase I explored the topic and scoped general directions, while phase II refined the key topics into specific themes that were in-

vestigated in-depth. Phase I also entailed practical observations of both companies and gave the opportunity to es- tablished friendly relations with the employees.

All interviewees were classified as Chinese and Thai people, depending on their identity documents (i.e., People's Republic of China passport or (PRC) Resident Identification Card, or Taiwan Passport or Republic of China Identity Card, Kingdom of Thailand passport or Thai National ID Card). Each interviewee was questioned about their cultural background, especially whether they identify as ethnic Thai-Chinese. Only one Thai person stated Chinese background, as her grandfather was Chinese born. All other interviewees stated their families are either "purely" Chinese or Thai respectively. Furthermore interviewees were also asked to provide basic personal information, such as age, job position, and work experience (abroad), and lengths of stay time in Thailand (for Chinese). The term 'employee' in this article is generically used to denote someone working in a company, regardless whether one holds managerial responsibility or ownership.

A total of 15 Chinese and 20 Thai people in JCIG company (a real estate and construction company), and 6 Chinese and 14 Thai people in CSYSJ company (a construction company) were interviewed. This covered all levels for both companies: senior management, middle management and front-line staff. Interviews were conducted in Thai or Chinese and audio-recorded and subsequently transcribed. The transcriptions were translated into English to provide the source for analysis. Quotes used in this article, are translations of verbatim transcript experts that render meaning of the source into the target language; this translation techniques tends to be closer to dynamic rather than formal equivalence (Nida \& Taber, 2003). All names of the interviewees and companies are pseudonyms to ensure confidentiality and anonymity.

\section{RESULT ANALYSIS}

Several themes emerged during the analysis of the empirical data, with regard to cultural differences, acculturation, and job satisfaction.

\section{Cultural Differences}

A notable difference in the conceptualization of time was detected between Chinese and Thai employees. Many Chinese interviewees felt that their Thai counterparts see planning ahead and time management not as important as they

did. In particular, Chinese managers thought that their Thai subordinates lacked an overview that would allow them to 
schedule individual tasks in line of an overall time frame.

" I feel they [Thai people] do not have a strong sense of time management, whether it is about due dates or completing work on schedule... I always need to plan time ahead of schedule, in case the Thai people are out of time. (Chinese Assistant of Sale Department, Ms. Belle)"

"If they get a task, they will not make a plan, e.g., how to start it or what steps to take... (Chinese Manager of Design Department, Mr. Leo)."

While indeed many Chinese implied that time is some form of resource that needs to be carefully managed, many Thai interviewees felt their Chinese colleagues are often not adequately focusing on details, especially when it comes to following rules and procedures. In contrast for Chinese interviewees' compliance with and flexibility in rule following was a crucial issue in day-to-day work practices. For many Chinese it was important to be able to adapt rules and procedures depending on circumstances, rather than merely complying with ignoring any other path in achieving a goal. Thai interviewees however pointed out that following rules and procedures ensures less risk of possible wrong doing, maximizing the extent of avoiding mistakes.

" The thinking of Chinese is very flexible... there are several roads to get to a destination. The Chinese will always look for the most convenient, with the least time, and the shortest path, but Thai people choose to take the main or conventional road, not a shortcut. (Chinese Manager of Hydropower Department, Mr. Tom)."

" Thai people are afraid to take risks and do not want to cause trouble... The simplest thing to them is to follow the rules. For example, if there is need to make any payment, it should be passed through by many levels, and get the approval of all levels. (Thai Manager of Administration Department, Ms. Emily)."

Many Thai interviewees were startled by their Chinese superior's strong top-down approach to managing. They felt that most Chinese mangers never consulted their subordinates and were not at ease with the apparent lack of discussions between the horizontal levels in their company. While Chinese managers expected obedience and not discussions, most Thai people felt obliged to establish two-way communication to be more effective in solving problems. Their view of organizational hierarchy seemed more harmonious, where individuals have also clearly designated positions, but are not as rigidly separated across different levels.

"Chinese manager always believe in themselves more than in others... Even if someone suggests a good idea to them, they still chose their own way... (Thai Leader of Customer Service Department, Ms. Anna)."

" In Thailand the boundary between levels is vague, but it doesn't mean there are no levels. It's just the relationship between superiors and subordinates are more like seniors and juniors... If there are any problems we just discuss them (Thai Staff of construction design department, Ms. Nicky)."

For many Thai interviewees their Chinese colleagues seemed competitive and eager to be successful by achieving their own goals. They felt that the Chinese often seem not to care about the feelings and needs of the others as they were too narrowly focusing on results. In contrast, Chinese interviewees saw the Thai consensus-seeking approach that aims to maintain harmony, by consulting at a much wider group-level, as inefficient and distracting from success.

" Thai people feel... the Chinese competition is fierce... The Chinese work division is very clear... They will finish the work separately. But Thai people we will work together and help each other (Thai Manager of Secretary Department, Ms. Patti)."

" I think Thailand is a very romantic nation. They are really loose in many aspects and almost have no concept of management (Chinese Manager of Design Department, Mr. Leo)."

\section{Acculturation}

On their own reflections, both Chinese and Thai interviewees tended to recount how they had experienced themselves resistance to unfamiliar settings that their crosscultural organization posed to them. They felt it was difficult to make concessions to their accustomed ways of doing and often saw the others ways as inappropriate.

"I think many Chinese still don't have a good understanding of the nature of Thai people. Like style of work and the life style... what Thai people really like... [and] need... but this is Thailand (Thai Staff of Human Resource Department, Ms. Linda)".

"If Thai people have a set of methods, they will always use these methods... We have brought a lot of advanced tools from China... but they still choose to use their original ways. It's not difficult to understand that most of them are reluctant to accept new things. (Chinese Manager of Construction Department, Mr. William)".

Nonetheless, some interviewees suggested that after a long time working together, they were aware of the cultural 
differences between Chinese and Thai and that they were willing to adjust trying to adapt to others way of doing. For some interviewees understanding of and adjustment to a different culture is seen as some form of compromise that can result in new ways, rather than a stark choice between their and the others culture.

"When I learned about the characteristics of Thai employees, I can only make the adjustments by myself, such as setting a more detailed plan, to ensure that the Thai people can move on according to the plan (Chinese Manager of Construction Department, Mr. William)".

"Sometimes it is hard to find the balance point, because sometimes-even if I make concessions, Thai people still cannot meet the standards that I set. In the end, I have to find another ways to make up for the rest (Chinese Manager of Design Department, Mr. Leo)".

Although these interview excerpts may give the impression of acculturation occurring in deliberate and orderly ways by constructively compromising, some interviewees implied that they experienced pressure to fit in that was not necessarily enriching. Notably some Thai employees felt that they had to change their ways of doing things, merely to retain their jobs and to get on in their company. While some employees reconstructed their own acculturation process in reference to their own culture, other employees appeared rationalizing their own acculturation in the light of the new culture they encountered.

"In my opinion, most of Chinese look down on Thai people... They have no confidence in our abilities. Therefore, I have to change myself, to change my way of working and way of speaking, to find a way that everyone can accept... instead of taking the way of not caring about other people (Thai Manager of Secretary Department, Ms. Patti)".

"Many Thai people may wonder why Chinese must work fast, but after you go to China, you will be well aware of the competition in China is very exciting and the pace of life is fast... (Thai Staff of Secretary Department, Ms. Patsy)".

\section{Job Satisfaction}

Overall, both Chinese and Thai employees, when asked whether their perception of cultural differences is influencing how satisfied they are with their job, most of them suggested there is no relationship between these issues. However, after deeper probing, most interviewees revealed signs of underlying frustration and disconcertment that other cultural ways of doing things were different and that the reasons behind this were partially unexplainable. Yet, it is precisely the recounting of actual or potential accultura- tion that appeared to give some interviewees strengths and clarity in coping with these cultural differences.

"No matter how you were in China before, but now you are in Thailand, you should try to learn and adapt to the Thai way... In fact, I think these differences will not affect me (Thai Staff of Purchase Department, Ms. Mary)".

"Everyone is more or less different... Sometimes we only need to change the mentality a little bit so that contradictions can be resolved. There is nothing that cannot be solved, but it depends whether we are willing to accept change (Thai Leader of Purchase Department, Ms. Kelly)".

The link between cultural differences in the workplace and job satisfaction, as it appears is more complex than one merely affects the other in a positive or negative way. Although interviewees appeared unable of giving psychological or anthropological explanations of cultural differences, they experienced them as real and in concrete ways in their day-to-day working life. Such experiences appeared to be more graspable when they were confronted with existing routine organizational problems. In other words, cultural differences reduce the ability to analyse and solve routine or common problems, which appeared to aggravate existing organizational problems and require more effort and determination.

"Although we may have some disagreements due to cultural differences... when these problems arise, it really increases the difficulty of our work... But it's not that we cannot fix it, it just needs more communication and exchange of opinions. (Chinese Translator of Project Department, Mr. Tony)".

Overall, those interviewees who appeared more adapted were less concerned with cultural differences negatively impacting their job satisfaction; they tended to also highlight the promising opportunities of working in crosscultural organizations. Such promises appeared to be both at intrinsic and extrinsic levels, such as self-realization in a job role and a potential career advancement elsewhere in international business settings.

\section{DISCUSSION AND CONCLUSION}

We have shown there are notable cultural differences in working practices that affect cross-cultural interaction between Chinese and Thai employees. Our empirical findings mirror Hofstede's (2003) grouping of China and Thailand for long-term orientation, masculinity/femininity, uncertainty avoidance, and power distance. Our findings, moreover, illustrate how Chinese seem to have a higher sense of future focus, as they emphasized more on future plan- 
ning and valued more organizational efforts that went beyond the immediacy of a situation than Thai employees. In contrast Thai employees valued more group harmony, unity and a reasonable work life balance and valued less getting ahead of colleagues and professional success than their Chinese counterparts. This is clearly in line with Hofstede's masculinity grouping that emphasizes higher levels of preference for material rewards for achievement, selfconfidence, success, and competitiveness in China than in Thailand.

We have also illustrated how in practice Thai employees seem to be adhering more to established rules and organizational norms and were less risk-taking than Chinese. While Chinese employees followed rules and codes of practices like everyone else, they were much more pragmatic, making adjustments as they saw fit, rather than mechanistically following a rule for its own sake. Furthermore Chinese maintained stronger boundaries between subordinates and superiors, expecting more obedience and stricter status or role divisions than Thai employees. In contrast Thai employees seemed to prefer to partially blur this distinction, with superiors expected to guide people rather than merely command them without any opportunity for discussion. These findings are both in line with Hofstede's uncertainty avoidance and power distance groupings respectively. China, accordingly, has much lower levels of uncertainty avoidance and a higher power distance than Thailand. Although the power distance in organizations both in Thailand and China is relatively high in contrast to other countries for instance in Western Europe and North America, Hofstede's (2003) grouping of China is only being slightly higher than Thailand. Nonetheless, our empirical analysis clearly shows that the differences in power distance can be understood as a notable concern for all interviewees, especially among Thai employees.

While most interviewees were not able to analytically explain cultural differences in terms of deeper values and underlying assumption (Schein, 2010), all of them readily recounted visible differences that related to their crosscultural interactions in their day-to-day work practices. Indeed many Thai and Chinese employees also showed insight to changes in their own cultural perspectives. The recounting of own acculturation and adaption over time working at their company displayed the classic two-stage pattern of denial and resistance followed by understanding and adjustment (Berry, 1997). Although, it might be beyond this study's scope to determine the precise form of adjustment, we suspect that integration and assimilation co-occurred as types of cultural adjustment to working in cross-cultural organizations.

Similar to Au et al. (1998) and Lu et al. (2012) who found that immigrants with higher levels of acculturation had also higher levels of job satisfaction, we found that both Chinese and Thai employees who appeared have adopted an integration or assimilation strategy that enabled them to be more positive and constructive about work-related problems than those who resisted adjustment. While this study did not deploy scaled measures to gauge job satisfaction, almost all interviewees were indicating that their level of job satisfaction was not directly affected by existing culture differences. However, deeper probing revealed that routine organization problems seemed to be aggravated by culture differences and finding solutions appeared to require extra efforts and more considerations. The extent to which these additional efforts were perceived as cumbersome and significantly reduced job satisfactions, at the point of dealing with common problems, may need future clarification. Yet, overall most interviewees treated the discussion surrounding job satisfaction as not reducible to a mere issue of discernible differences in cross-cultural interactions. In line with Weiss et al. (1967), both Chinese and Thai employees readily pointed to other factors, such as income, lifestyle, career advancement, and personal accomplishments.

\section{RECOMMENDATIONS FOR PRACTITIONERS}

Working in a cross-cultural organization always requires special consideration and of course adequate language and cultural training. We recommend a cross-cultural awareness strategy. This would entail facilitating a basic understanding of other people's and one's own culture. Adequate learning activities may indeed start with appreciating of each others culinary practices or other visible cultural aspects, but must consequently lead to a deeper understanding of each others values that influence work practices and outlooks on life. Yet, it is crucial that such value explorations are not undertaken as a moral or judgmental exercise. Instead its purpose must be to equip the learner with explanatory powers that would rationalize the difference in behaviour as well as sensitize each other toward differences.

Moreover we recommend not to over-psychologize problems resulting from cross-cultural interactions, but to keep a perspective on the wider organizational context. Such cross-cultural awareness strategies can improve cross-cultural interaction and help people to reduce dis- 
satisfaction that stems from cross-cultural interactions. However, it cannot remedy wider organizational problems, regardless whether they are obscured or hidden by crosscultural conflict or misunderstandings. On the contrary, as shown in this article, existing normal organizational problems can be aggravated or prolonged by cross-cultural interactions and thereby reduce job satisfaction. This implies that management needs to be particularly focused on disentangling the potential cross-cultural issues from other organizational problems.

Overall, we would highlight that any cross-cultural awareness strategy is not merely a learning activity, but a long-term organizational strategy that allows adequately coping with differences and potentially seeing strength and enrichment in differences. Its aim is not to eradicate differences in cross-cultural organizations, but to guide individuals in developing integration competency depending on their own educational background, professional ability and previous cross-cultural experience.

\section{Acknowledgment}

The author is grateful to all interviewees for their time and effort of telling their experiences, as well as to senior management in both companies for granting us research access. The author is indebted to Dr Andreas Hild for his detailed comments on this paper and his guidance during the research design and fieldwork stages.

\section{REFERENCES}

Ahlstrom, D., Young, M.N., Ng, F.M., \& Chan, C.M. 2004. High technology and globalization challenges facing overseas Chinese entrepreneurs. SAM Advanced Management Journal, 69(2): 28-37.

Ardyanfitri , H., \& Wahyuningtyas, R. 2016. The influence of job career development opportunities, training, occupational safety and health on the job satisfaction of employees in the Telkom University. Journal of Administrative and Business Studies, 2(5): 231-240. DOI: 10.20474/jabs-2.5.3

Au, A.Y.W., Garey, J.G., Bermas, N., \& Chan, M.M. 1998. The relationship between acculturation and job satisfaction among Chinese immigrants in the New York city restaurant business. International Journal of Hospitality Management, 17(1): $\quad$ 11-21. DOI: 10.1016/s0278-4319(97)00040-6

Berry, J.W. 1997. Immigration, acculturation, and adaptation. Applied Psychology, 46(1): 5-34.

DOI: $10.1111 / \mathrm{j} .1464-0597.1997 . t b 01087 . x$

Bo Shing, L.A., \& Xiaodie P.J. 2017. Exploring the relationship between leadership, organizational culture, trust, and effec- tiveness of knowledge sharing by forced learning. Journal of Administrative and Business Studies, 3(2): 89-104.

DOI: 10.20474 /jabs-3.2.4

Bonache, J. 2005. Job satisfaction among expatriates, repatriates and domestic employees: The perceived impact of internaassignments on work-related variables. Personnel Review, 34(1): 110-124. DOI: /10.1108/00483480510571905

Briggs, C.L. 1986. Learning how to ask: A sociolinguistic appraisal of the role of the interview in social science research. Cambridge, UK: Cambridge University Press.

Broad of Investment. 2017. PRC investment projects submitted to BOI. URL: goo.gl/KTNgiz. Last accessed on 1 June 2016. Burusratanaphand, W. 1995. Chinese identity in Thailand. Southeast Asian Journal of Social Science, 23(1): 43-56.

DOI: $10.1163 / 030382495 \times 00042$

Ea, E.E., Griffin, M.Q., L' eplattenier, N., \& Fitzpatrick, J.J. 2008. Job satisfaction and acculturation among Filipino registered nurses. Journal of Nursing Scholarship, 40(1): 46-51. DOI: 10.1111/j.1547-5069.2007.00205.x

Epifanova, S., \& Hild, A. 2015. Contemporary issues in cross-cultural business interaction amongst office and managerial staff in Thailand. International Journal of Business and Economics, 7(1): 131-145.

Franco, A. 2015. Book review: A history of the Thai-Chinese jeffrey sng and pimpraphai bisalputra. ASEAN Journal of Man- agement \& Innovation, 2(2): 101-105.

Gelfand, M.J., Erez, M., \& Aycan, Z. 2007. Cross-cultural organizational behavior. Annual Review of Psychology, 58(1): 479- 514. DOI: 10.1146/annurev.psych.58.110405.085559

Hofstede, G. 2003. Culture's consequences: Comparing values, behaviors, institutions and organizations across na- tions. London, UK: Sage Publications. 
Journal of Organizational Behavior, 24(2): 159-179. DOI: 10.1002/job.186

Hui, C.H., \& Yee, C. 1999. The impact of psychological collectivism and workgroup atmosphere on Chinese employees' job satisfaction. Applied Psychology, 48(2): 175-185. DOI: 10.1111/j.1464-0597.1999.tb00056.x

Hui, M.K., Au, K., \& Fock, H. 2004. Empowerment effects across cultures. Journal of International Business Studies, 35(1): 46-60. DOI: 10.1057 /palgrave.jibs.8400067

Kirkman, B.L., Lowe, K.B., \& Gibson, C.B. 2006. A quarter century of culture's consequences: A review of empirical research incorporating Hofstede's cultural values framework. Journal of International Business Studies, 37(3): 285-320.

DOI: $10.1057 /$ palgrave.jibs.8400202

Kirkman, B., \& Law, K. 2005. International management research in AMJ: Our past, present, and future. Academy of Man- agement Journal, 48(3): 377-386. D0I: 10.5465/amj.2005.17407902

Law, J. 2004. After methods: Mess in the social science research. London, UK: Routledge.

Lewis, R.D., \& Gates, M. 2005. Leading across cultures. London, UK: Nicholas Brealey.

Li, M., Ruangkanjanases, A., \& Chen, C. 2014. China's foreign direct investment in Thailand-current status and future prospects. International Journal of Trade, Economics and Finance, 5(4): 296-304. D0I: 10.7763/ijtef.2014.v5.387

Lu, Y., Samaratunge, R., \& Härtel, C.E. 2012. The relationship between acculturation strategy and job satisfaction for professional Chinese immigrants in the Australian workplace. International Journal of Intercultural Relations, 36(5): 669-681.

DOI: $10.1016 /$ j.ijintrel.2012.04.003

McCaughey, D., \& Bruning, N.S. 2005. Enhancing opportunities for expatriate job satisfaction: HR strategies for foreign as- $\quad$ signment success. Human Resource Planning, 28(4): 21-30.

Nida, E.A., \& Taber, C.R. 2003. The theory and practice of translation. Leiden, Netherlands: Brill.

Robert, C., Probst, T.M., Martocchio, J.J., Drasgow, F., \& Lawler, J.J. 2000. Empowerment and continuous improvement in the United States, Mexico, Poland, and India: Predicting fit on the basis of the dimensions of power distance and individual- $\quad$ ism. Journal of Applied Psychology, 85(5): 643-658. D0I: 10.1037//0021-9010.85.5.643

Schein, E. 2010. Organizational culture and leadership. San Francisco, CA: John Wiley \& Sons.

Spradley, J. 1979. The ethnographic interview. London, UK: Rinehart Winston.

Tsui, A.S., Nifadkar, S.S., \& Ou, A.Y. 2007. Cross-national, cross-cultural organizational behavior research: Advances, gaps, and recommendations. Journal of Management, 33(3): 426-478. DOI: 10.1177/0149206307300818

Weiss, D.J., Dawis, R.V., \& England, G.W. 1967. Manual for the minnesota satisfaction questionnaire. Minnesota Studies in Vocational Rehabilitation, 22: 1-125.

Yeung, H.W. 2006. Change and continuity in Southeast asian ethnic Chinese business. Asia Pacific Journal of Management, 23(3): 229-254. DOI: 10.1007/s10490-006-9007-2

Yusof, H.S.M., Munap, R., Badrillah, M.I.M., Ab Hamid, N.R., \& Khir, R.M. 2017. The relationship between organizational cul- ture and employee motivation as moderated by work attitude. Journal of Administrative and Business Studies, 3(1): 21-25. DOI: $10.20474 /$ jabs-3.1.3

— This article does not have any appendix. - 